OPEN ACCESS

Edited by:

Shuang Ye,

Shanghai Jiao Tong University, China

Reviewed by:

Cheng-De Yang,

Shanghai Jiao Tong University, China

Hua Cao,

Shanghai Jiao Tong University, China

${ }^{*}$ Correspondence:

Bing Yan

yb420@163.com

tThese authors have contributed equally to this work and share first authorship

Specialty section:

This article was submitted to

Rheumatology,

a section of the journal

Frontiers in Medicine

Received: 10 December 2021

Accepted: 31 December 2021

Published: 24 January 2022

Citation:

Hu H, Yang H, Liu Y and Yan B (2022)

Pathogenesis of Anti-melanoma

Differentiation-Associated Gene 5 Antibody-Positive Dermatomyositis: A Concise Review With an Emphasis on

Type I Interferon System.

Front. Med. 8:833114.

doi: 10.3389/fmed.2021.833114

\section{Pathogenesis of Anti-melanoma Differentiation-Associated Gene 5 Antibody-Positive Dermatomyositis: A Concise Review With an Emphasis on Type I Interferon System}

\author{
Huifang $\mathrm{Hu}^{\dagger}$, Hang Yang ${ }^{\dagger}$, Yi Liu and Bing Yan * \\ Department of Rheumatology and Immunology, Rare Diseases Center, Frontiers Science Center for Disease-Related \\ Molecular Network, Institute of Immunology and Inflammation, West China Hospital, Sichuan University, Chengdu, China
}

Anti-melanoma differentiation-associated gene 5 antibody-positive dermatomyositis (MDA5 $\left.{ }^{+} \mathrm{DM}\right)$ is typically characterized by cutaneous manifestations, amyopathic or hypomyopathic muscle involvement, and a high incidence of rapid progressive interstitial lung disease (RP-ILD). However, the exact etiology and pathogenesis of this condition has yet to be fully elucidated. Melanoma differentiation-associated gene 5 (MDA5), as the autoantigen target, is a member of the retinoic acid-inducible gene-I (RIG-I) family. The MDA5 protein can function as a cytosolic sensor that recognizes viral doublestrand RNA and then triggers the transcription of genes encoding type I interferon (IFN). Therefore, it was presumed that viruses might trigger the overproduction of type I IFN, thus contributing to the development of MDA5 ${ }^{+} \mathrm{DM}$. Emerging evidence provides further support to this hypothesis: the increased serum IFN $\alpha$ level was detected in the patients with MDA5 ${ }^{+} \mathrm{DM}$, and the type I IFN gene signature was upregulated in both the peripheral blood mononuclear cells (PBMCs) and the skin tissues from these patients. In particular, RNA sequencing revealed the over-expression of the type I IFN genes in blood vessels from MDA5 ${ }^{+}$DM patients. In addition, Janus kinase (JAK) inhibitors achieved the promising therapeutic effects in cases with interstitial lung disease (ILD) associated with $\mathrm{MDA5}^{+} \mathrm{DM}$. In this review, we discuss the role of the type I IFN system in the pathogenesis of $\mathrm{MDA}^{+} \mathrm{DM}$.

Keywords: anti-MDA5 antibody, MDA5 ${ }^{+}$DM, CADM, type I IFN, IFN I system, pathogenesis

\section{INTRODUCTION}

Dermatomyositis (DM) is a form of idiopathic inflammatory myopathy (IIM) that is characterized by chronic systemic inflammation and predominantly affects the skeletal muscle, skin, joints, and lungs. According to the different myositis-specific autoantibodies, there are several highly heterogeneous DM phenotypes $(1,2)$. In particular, patients with anti-melanoma differentiation-associated gene 5 (MDA5) autoantibodies had the typical rashes of DM, but the mild or even absent muscle involvement, and an increased risk of rapid progressive interstitial lung disease (RP-ILD), a condition that often leads to high mortality (3-5). 
According to previous studies, the mortality of RP-ILD related to anti-melanoma differentiation-associated gene 5 antibodypositive dermatomyositis $\left(\mathrm{MDA}^{+} \mathrm{DM}\right)$ in the first year ranged from $34.8 \%-80 \%(3,6,7)$.

The exact pathogenesis of $\mathrm{MDA}^{+} \mathrm{DM}$ remains largely unknown, although the interaction of environmental factors and genetic factors are generally considered as the initiating event (8). Recently, more emerging evidence has suggested that type I interferon (IFN) could play a critical role in $\mathrm{MDA}^{+} \mathrm{DM}$. Thus, we summarize the current evidence regarding the role of IFN I system in $\mathrm{MDA}^{+} \mathrm{DM}$.

\section{MDA5 AND THE IFN I SYSTEM}

\section{The Function of MDA5}

The anti-MDA5 antibody was first discovered in a Japanese patient cohort with clinically amyopathic dermatomyositis (CADM) in 2005 (9). Subsequent studies demonstrated that MDA5, the autoantigen target, was coded by the interferoninduced helicase $\mathrm{C}$ domain-containing protein 1 (IFIH1) gene. MDA5, as a member of the retinoic acid-inducible gene-I (RIG-I) family (10-14), can recognize viral dsRNA (14-16). After activation, MDA5 binds to an adaptor, mitochondrial antiviral signaling protein (MAVS), on the outer membrane of mitochondria, and then activates the interferon regulatory family 3 (IRF3) via tumor necrosis factor receptor-associated factor 3 (TRAF3) and TANK-binding kinase 1 (TBK1) (10, 14, 16-19). Finally, these events induce the production of enormous quantities of type I IFNs, thus causing antiviral properties (20-22).

\section{The IFN I System}

Type I IFNs are polypeptides that exhibit antiviral properties and were first described over 60 years ago (23). Subsequently, these polypeptides were found to play the critical roles in inflammation, cancer, and autoimmune diseases (10, 21, 24). Generally, the type I IFN system is broadly defined as the type I IFNs themselves, along with their inducers, cells, and other molecules involved in the pathways that lead to the production and functional effects of type I IFNs (25). In humans, type I IFNs predominantly consist of IFN $\alpha$ and IFN $\beta$, although there are less well known subtypes, including IFN $\omega$, IFNא, and IFNe. Almost all nucleated cells are capable of producing IFN $\beta$, while plasmacytoid dendritic cells (pDCs) are the predominant producers of IFN $\alpha$ in most situations (26). The production of type I IFN is mediated by toll-like receptors (TLRs) (TLR-dependent) or other systems, such as RIG-I and MDA5 (TLR-independent), depending on the nature of the inducers involved $(10,21)$. TLR3/7/8/9, the endosomal membrane receptors expressed in many innate immune cells, are the predominant TLRs in the TLR-dependent pathways. In particular, TLR7/9 are expressed preferentially in the endosomal membranes of pDCs $(21,22)$.

IFN $\alpha / \beta$ bind to the IFN $\alpha$ receptor (IFNAR, composed of IFNAR1 and IFNAR2 subunits) thereby causing activation of receptor-associated tyrosine kinases like Janus kinase 1/2 (JAK1/2) and tyrosine kinase 2 (TYK2). Then, JAK1 and TYK2 can phosphorylate the transcription factors known as signal transducer and activator of transcription 1 (STAT1) and STAT2. Phosphorylated STAT1 and STAT2 dimerize and translocate to the nucleus where they form a trimolecular complex referred to as IFN-stimulated gene factor 3 (ISGF3) with IFN-regulatory factor 9 (IRF9) $(13,24,27)$. This complex binds specific elements known as IFN-stimulated response elements (ISREs). This binding initiates the transcription of IFN-stimulated genes (ISGs), such as Mx1, IFIT2, and ISG15 (28, 29). The expression of ISGs, the so-called IFN signature, can target the distinct steps in the viral replication cycle (30). Type I interferon signaling is tightly regulated by various pathways such as post-translational modification of signaling molecules and epigenetic modification of gene expression. Aberrant IFN signaling is widely associated with pathological conditions such as autoimmune diseases, chronic infection and cancer (13).

Except direct antiviral properties, type I IFN augments the innate and adaptive response by enhancing the cytotoxic effect of natural killer (NK) cells and intracellular killing by macrophages, stimulating dendritic cells (DCs) to mature into effective antigen presenting cells (APCs), and increasing expression of class I and II major histocompatibility complex (MHC). Type I IFNs activate a number of immune cells including macrophages, DCs and $T$ cells. DCs matured and stimulated by IFN $\alpha / \beta$ express co-stimulatory molecules (e.g., CD80 and CD86), produce chemokines (e.g., CXCL9 and CXCL10) and cytokines (e.g., IL15), and mount an enhanced antiviral immune reaction. Thus, the effector function of T and B cells are promoted by type I IFN. Subsequently, type I IFN can promote immunoglobulin (Ig) class switching and antibody production. Meanwhile the generation of memory cells is augmented $(26,31)$.

\section{FOOTPRINTS OF IFN I SYSTEM IN ORGANS INVOLVED IN MDA5 ${ }^{+}$DM}

\section{Skin}

Individuals with $\mathrm{MDA}^{+} \mathrm{DM}$ have a distinctive mucocutaneous phenotype, involving cutaneous ulceration and palmar papules $(4,32,33)$. Interestingly, IFNא, which is highly expressed in keratinocytes, has been shown to expressed at high levels in the skin of patients with $\mathrm{MDA}^{+} \mathrm{DM}(34,35)$. A previous study showed that IFN火 enhanced IFN responses and photosensitivity in the pathological progression of cutaneous lupus erythematosus (36). Therefore, the potential role of keratinocytes and IFNK in the skin of patients with $\mathrm{MDA}^{+} \mathrm{DM}$ might be more substantial than that of IFN $\alpha$. Histological analysis of the skin tissues from these patients revealed the significant perivascular inflammation and Mxl expression in the blood vessels of the superficial and deep dermis (37). Skin IFN I transcriptomic signature analysis in three MDA5 ${ }^{+}$DM patients further found that FIT2C, CXCL10, and IFIH1, were the most highly upregulated genes in the skin tissue (35).

The pathogenic mechanism underlying cutaneous ulcers in $\mathrm{MDA}^{+} \mathrm{DM}$ is known to involve vasculopathy. Pathological evidence for vasculopathy has been found in the biopsies of cutaneous ulcers from patients with $\operatorname{MDA}^{+} \mathrm{DM}(33,38)$. 
Biomarkers related to endothelial damage, including serum soluble intercellular adhesion molecule-1 (sICAM-1), soluble vascular cell adhesion molecule-1 (sVCAM-1), endothelin-1 (ET1 ), and von Willebrand factor (vWF), were found to be expressed at high levels in patients with $\mathrm{MDA}^{+} \mathrm{DM}$. Furthermore, the circulating levels of ET-1 were positively correlated with the levels of Galectin-9 (Gal-9) in MDA5 ${ }^{+}$DM patients (39). Gal-9 mRNA expression were positively correlated with the mRNA levels of IFN-I inducible genes in PBMCs from $\mathrm{MDA}^{+}$DM patients (40). Collectively, IFN I system may be suggested to be involved in the skin damage in patients with $\mathrm{MDA}^{+} \mathrm{DM}$.

\section{Muscle}

The clinical signs of myositis are frequently mild or absent in patients with $\operatorname{MDA}^{+} \operatorname{DM}(3,4,6)$. In a previous study, Allenbach et al. analyzed the expression of six ISGs in muscle, including OAS1, ISG15, OAS3, Mx1, RIG-I, and IFIH1. Although the IFN signature was up-regulated in groups of patients with $\mathrm{MDA5}^{+} \mathrm{DM}$ and classic DM when compared with normal muscle, the up-regulation of ISGs was less significantly in MDA $^{+}$DM patients than that in classic DM patients (41). A study from China investigated the mitochondrial changes and MAVS-type I IFN signaling pathways in the muscles of MDA5 ${ }^{+}$ DM patients (42). These authors found that the IFN-I inducible proteins (MDA5, MAVS, IRF7, and ISG15) were overexpressed in the muscles of $\mathrm{MDA}^{+} \mathrm{DM}$ patients, suggesting that the MAVStype I IFN pathway is broadly involved in the muscle pathology of $\mathrm{MDA}^{+} \mathrm{DM}$.

\section{Lung}

ILD is the most striking systemic complication in patients with $\mathrm{MDA}^{+} \mathrm{DM}$ and could present as worsening respiratory distress, hypoxemia, and radiographic deterioration over the course of days or weeks (4). A recent study demonstrated that serum levels of IFN $\alpha$ and ferritin were significantly higher in $\mathrm{MDA}^{+} \mathrm{DM}$ patients, and serum IFN $\alpha$ could be used as a biomarker for $\mathrm{MDA}^{+}$DM patients with RP-ILD (43).

The significance of anti-MDA5 antibody in $\mathrm{MDA}^{+} \mathrm{DM}$ may represent another piece of important evidence for the involvement of IFN I system in this disorder. A recent study revealed that RNA-containing immune complexes (ICs) formed by MDA5 and anti-MDA5 antibody could stimulate IFN $\alpha$ production in vitro. Further co-immunoprecipitation verified the interaction between ICs and TLR7. Confocal images also showed co-localization of ICs with TLR7, thus suggesting that the MDA5 ICs could induce the production of IFN $\alpha$ via TLR7 (44). A growing body of data now suggests that the level of anti-MDA5 antibody correlates with disease activity and prognosis (32, 45, 46). Furthermore, Lian X et al. proposed the FLAIR risk score model, consisting of ferritin, lactate dehydrogenase, anti-MDA5 antibody, high-resolution CT imaging score, and RP-ILD, to predict the prognosis in patients with CADM-ILD. In this model, high titers of anti-MDA5 antibody were considered to be one of the weighting factors, which suggests a poor prognosis (47).

Downstream chemokines and cytokines of IFN I system are known to be upregulated in $\mathrm{MDA}^{+} \mathrm{DM}$ patients with ILD. In a hierarchical cluster analysis of cytokine profiles, levels of
IFN-related cytokines (IFN $\gamma, \operatorname{IFN} \alpha$, and IP-10, an IFN-induced proteins) were significantly higher in the anti-MDA5 antibodypositive subgroup patients than in the anti-TIF1 $\gamma$ antibodypositive subgroup patients (48). Elevated levels of CX3CL1 were found in ILD patients associated with $\mathrm{MDA}^{+} \mathrm{DM}$ and were correlated with the titers of the anti-MDA5 antibodies $(49,50)$. Type I IFN could induce CX3CL1 expression in pulmonary vascular endothelial cells (51). In a previous study, CX3CL1 level was correlated to $\mathrm{CD}^{+}{ }^{+} \mathrm{T}$ cells counts and the severity of lung parenchyma impairment (52). CX3CL1 was reported to enhance endothelial transmigration of non-classical monocytes in the lungs of patients with ILD, the recruitment of M2 macrophages, thereby promoting local pulmonary fibrosis $(53,54)$.

Given the role of the type I IFN pathway in $\mathrm{MDA}^{+} \mathrm{DM}$, it is reasonable that JAK inhibitors may represent a potential therapeutic option for ILD complications. Five refractory RPILD cases associated with $\mathrm{MDA}^{+} \mathrm{DM}$ received a combination therapy including tofacitinib and achieved a significant higher survival rate (55). Further, in early-stage $\mathrm{MDA}^{+}$DM-ILD patients who received JAK inhibitors, a significantly increased survival rate was observed (56). Another study described two refractory JDM patients with anti-MDA5 antibodies who were treated with a JAK inhibitor (tofacitinib). Both patients demonstrated a significant reduction in the IFN score and improvement in disease activity (57). However, this treatment effect needs to be investigated further.

\section{THE MECHANISMS UNDERLYING IFN I PATHWAY IN MDA5 ${ }^{+}$DM}

As mentioned above, type I IFN system may be over-activated in $\mathrm{MDA}^{+}$DM. However, the exact underlying mechanisms has yet to be elucidated. We propose that environmental factors may trigger the aberrant production of type I IFN in genetically susceptible individuals. This process will subsequently induce type I IFN-meditated cellular pathology.

\section{Environmental and Genetic Factors}

Viral infections are speculated to be an initiating factor in the development of MDA5+ DM. RNA viruses, such as the coxsackie B virus, parvovirus B19, and hepatitis C virus, have been reported to be involved in myositis (58-60), all of which could activate MDA5 (14). Recently, two independent studies have suggested that environmental factors can influence the onset of MDA5 ${ }^{+}$DM: One epidemiological study in Japan showed that the presence of anti-MDA5 antibody in CADM patients was negatively associated with the population size of their city (61). The other study reported that patients with MDA5 ${ }^{+} \mathrm{DM}-$ ILD were mainly identified between October and March in individuals residing near freshwater (62).

With regards to genetic risk factors, frequencies of HLA$\mathrm{DRB}^{*} 0401$ and ${ }^{*} 1202$ were significantly higher in a cohort of Chinese Han subjects with MDA5 ${ }^{+}$PM/DM (63), while HLADRB ${ }^{*} 0101$ and ${ }^{*} 0405$ were associated with susceptibility to this disorder in the Japanese population (64). Ethnic differences may have an impact on the propensity of this disease, in spite 
of no association between $\mathrm{MDA}^{+} \mathrm{DM}$ and the HLA allele region analyzed in the Caucasian population (65). Interestingly, a genome-wide association study of 592 patients with IIM revealed a splice variant of the WDYF4 gene in CADM patients. This variant and tr-WDFY4 (a truncated isoform of WDFY4) were shown to bind TLR3, TLR4, TLR9, and MDA5 and could enhance activation of the NF- $\mathrm{KB}$ pathway (66).

\section{IFN I-Meditated Cellular Pathology}

Type I IFN can function as the central liaison between the innate and adaptive immune systems, which is the essential player in autoimmune diseases.

Type I IFN can exert direct influence on T cells. Peripheral blood lymphocytes are often reduced when serum levels of IFN increased. A previous study showed that a significantly higher proportion of $\mathrm{MDA}^{+} \mathrm{DM}$ patients had reduced peripheral $\mathrm{CD}^{+}{ }^{+}$and $\mathrm{CD}^{+}{ }^{+} \mathrm{T}$ cell counts (46). A more recent study revealed that $\mathrm{CD}^{+}{ }^{+} \mathrm{CXCR}^{+} \mathrm{T}$ cells were increased in PBMCs and bronchoalveolar lavage fluid in patients with IIM-ILD. Patients with high $\mathrm{CD}^{+}{ }^{+} \mathrm{CXCR}^{+}(\geq 30 \%)$ were more likely to be positive for the anti-MDA5 antibody. In vitro, peripheral CD4 ${ }^{+}$CXCR4 ${ }^{+}$ $\mathrm{T}$ cells produced high levels of IL-21, which were found to meditate the proliferation of pulmonary fibroblasts and were inhibited by a JAK inhibitor (67).

Type I IFN could induce DCs to produce B cell activating factor (BAFF), which plays a critical role in B cell survival and $\operatorname{Ig}$ class switching $(31,68)$. Notably, the upregulation of BAFF following viral infection is IFN-dependent. Monocytes have been shown to release BAFF in response to IFN treatment $(68,69)$. Matsushita et al. revealed that $\mathrm{MDA}^{+} \mathrm{DM}$ patients exhibited increased levels of BAFF when compared with healthy controls. Furthermore, serum BAFF levels in $\mathrm{MDA}^{+} \mathrm{DM}$ patients were reduced following immunosuppressive therapy along with the levels of anti-MDA5 antibody and ferritin (70). In addition, Zhang et al. found that IFN $\alpha$ was correlated to BAFF in patients with $\mathrm{MDA}^{+} \mathrm{DM}$ and that increased levels of BAFF were associated with higher concentrations of Krebs von den Lungen-6 (KL-6) (71), a potential biomarker that reflects the severity of connective tissue disease-associated ILD (72). It has been shown that an excess of BAFF may contribute to the autoreactive B cells survival, thereby causing autoimmune diseases (73).

Although the pathogenicity of the anti-MDA5 autoantibody has not to be fully elucidated, there are two lines of evidence which are shedding the light: One is that RNA-containing ICs, formed by MDA5 and anti-MDA5 antibody, may enhance type I IFN self-circulation as endogenous inducers. A recent Chinese study revealed that MDA5 ICs, in patients with either DM or SLE, could activate pDCs and stimulate the production of IFN $\alpha$ in vitro. These authors also confirmed that MDA5 ICs interact with TLR7 to induce the production of IFN $\alpha$ (44). The other is that $\operatorname{IgA}$ and $\operatorname{IgG}$ are shown to be the major isotypes of MDA5 autoantibodies in patients with $\mathrm{MDA}^{+} \mathrm{DM}$. One study showed that DM/CADM patients with anti-MDA5 IgG1 subclasses were correlated to significantly higher occurrence rates of acute interstitial pneumonia, serum levels of lactate dehydrogenase $(\mathrm{LDH})$, and ferritin. Higher mortality rates were detected in patients who were positive for anti-MDA5 IgG1 and IgG4, thus suggesting that these two IgG subtypes might serve as useful biomarkers for predicting mortality in patients with DM-ILD (74).

Type I IFN also induces the development of autoinflammation $(14,75)$. Monocytes and macrophages are both essential parts of this process. A previous case report detected macrophages in the alveoli, bone marrow, liver, and spleen of a MDA5 ${ }^{+} \mathrm{DM}$ patient with RP-ILD and hyper-ferritin (76). In addition, levels of serum soluble CD206, a marker of alternatively activated macrophages, were increased in ILD patients with $\mathrm{MDA}^{+}$ $\mathrm{DM}$ and were associated with the poor prognosis (77). In this study, the authors observed the marked accumulation of $\mathrm{CD}^{2} 06^{+}$macrophages infiltrated into the airspace of a fatal DM-ILD case compared with a surviving patient with CADMILD and an early lung cancer patient, thus suggesting the potential role of macrophages in the disease progression of MDA5 $^{+}$DM. As discussed above, type I IFN can induce the expression of CX3CL1 in pulmonary vascular endothelial cells (51). Further studies also verified that CX3CL1 could drive the migration of non-classical monocytes into lung tissue, thereby meditating local fibrotic process (54). An integrated miRNA-mRNA association analysis using circulating monocytes from MDA5 $^{+}$DM patients identified ILD, IFN $\beta$, TLR3, TLR7, TLR9, and the Spi-1 proto-oncogene encoding PU.1 (a transcription factor regulating the differentiation of monocytes), as upstream regulators of $\mathrm{MDA}^{+} \mathrm{DM}$ (78). These authors also found that activated monocytes/macrophages contributed to cytokine storms in patients with $\mathrm{MDA} 5^{+} \mathrm{DM}$ with ILD (78). On the other hand, serum levels of C-C motif ligand 2 (CCL2, a chemokine that is also referred to as monocyte chemoattractant protein-1) and IFN $\beta$, were both reduced following the treatment of survivors with $\mathrm{MDA}^{+} \mathrm{DM}$ with ILD. It has been suggested that CCL2 guides monocytes along a chemokine gradient to the location of inflammation, such as the lungs $(79,80)$.

Above all, we make up a jigsaw puzzle of $\mathrm{MDA}^{+} \mathrm{DM}$ pathogenesis with an emphasis on the role of type I IFN (Figure 1). In genetically susceptible individuals, unknown environmental triggers are recognized by the MDA5 protein. This process leads to dysregulation in the type I IFN system. As the liaison between the innate and adaptive immune response, the overproduction of type I IFN promotes the antigen presentation of DCs. In addition, type I IFN activates the differentiation of $\mathrm{T}$ cells and $\mathrm{B}$ cells. Then, pathogenic autoantibodies are generated by plasma cells. RNA-containing ICs formed by MDA5 and the anti-MDA5 antibody might act as the endogenous inducers for type I IFN, thus aggravating the vicious circle of type I IFN system overactivation. Furthermore, the activation of monocytes and macrophages might contribute to the development of RP-ILD.

\section{DISCUSSION}

Accumulating evidence over the past few years has revealed that the dysregulation type I IFN system could 


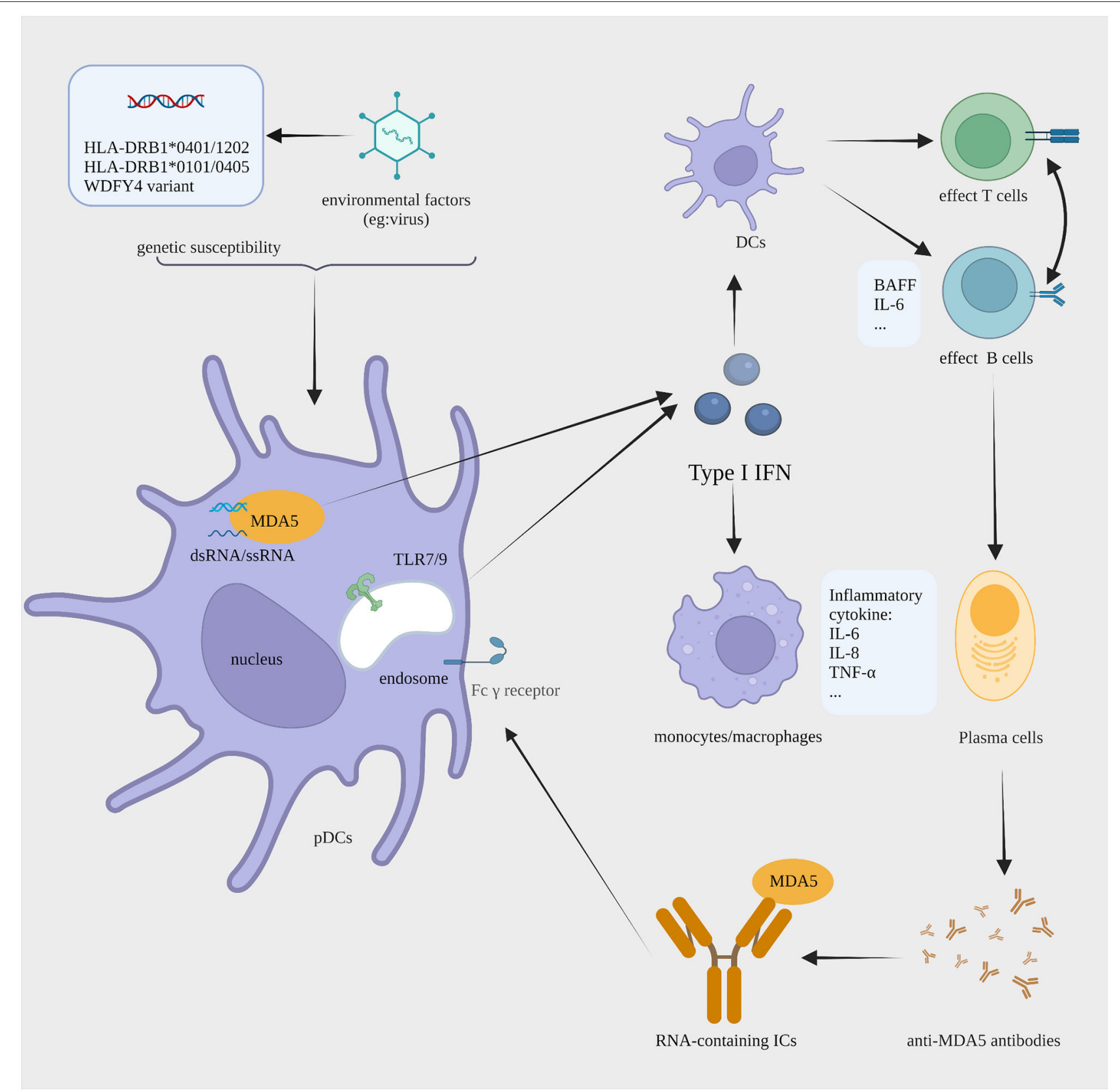

FIGURE 1 | The proposed IFN I-mediated cellular pathology in MDA5 ${ }^{+}$DM. In individuals with a background of susceptibility genes $\left(H L A-D R B 1{ }^{*} 0101\right.$ and ${ }^{*} 0405$, HLA-DRB1 ${ }^{*} 0401$ and ${ }^{*} 1202$, or a variant in WDFY4), the dsRNA of unknown viral trigger is sensed by MDA5, causing the aberrant production of type I IFN by pDCs. Type I IFN enhances the antigen presentation of DCs, the effector function of T and B cells, and antibody production by plasma cells. Anti-MDA5 antibodies are generated in large amounts and then recognize MDA5, forming RNA-containing ICs. The ICs can activate type I IFN production via TLR7. All this promotes continued type I IFN production that sustains pathogenesis by a process with features of a vicious circle. Moreover, monocyte and macrophage may contribute to the development of RP-ILD. IFN, interferon; MDA5+ DM, anti-melanoma differentiation-associated gene 5 antibody-positive dermatomyositis; pDCs, plasmacytoid dendritic cells; DCs, dendritic cells; ICs, immune complexes; TLR, toll-like receptor; RP-ILD, rapid progressive interstitial lung disease. The figure is created with BioRender.com.

play the role in the pathogenesis of $\mathrm{MDA}^{+} \mathrm{DM}$. Given the role of the type I IFN system in $\mathrm{MDA}^{+}$ $\mathrm{DM}$, therapies that target the type I IFN pathway, such as JAK inhibitors, have shown potential therapeutic effect. Except for JAK inhibitors, sifalimumab, one of the anti-IFNa monoclonal antibodies, has shown a target neutralization of a type I IFN signature in the blood of DM and PM patients in a phase Ib 
clinical trial (81). Thus, anti-IFN $\alpha$ therapies and other new targets of type I IFN pathway would be new treatment options.

\section{AUTHOR CONTRIBUTIONS}

$\mathrm{HH}$ and $\mathrm{HY}$ drafted the manuscript and figure. YL and BY supervised the work and revised the manuscript. All authors contributed to the article and approved the submitted version.

\section{REFERENCES}

1. Dalakas MC. Inflammatory muscle diseases. N Engl J Med. (2015) 372:173447. doi: 10.1056/NEJMra1402225

2. Lundberg IE, de Visser M, Werth VP. Classification of myositis. Nat Rev Rheumatol. (2018) 14:269-78. doi: 10.1038/nrrheum.2018.41

3. Huang K, Vinik O, Shojania K, Yeung J, Shupak R, Nimmo M, et al. Clinical spectrum and therapeutics in Canadian patients with anti-melanoma differentiation-associated gene 5 (MDA5)positive dermatomyositis: a case-based review. Rheumatol Int. (2019) 39:1971-81. doi: 10.1007/s00296-019-04398-2

4. Kurtzman DJB, Vleugels RA. Anti-melanoma differentiation-associated gene 5 (MDA5) dermatomyositis: a concise review with an emphasis on distinctive clinical features. J Am Acad Dermatol. (2018) 78:77685. doi: 10.1016/j.jaad.2017.12.010

5. McHugh NJ, Tansley SL. Autoantibodies in myositis. Nat Rev Rheumatol. (2018) 14:290-302. doi: 10.1038/nrrheum.2018.56

6. Allenbach Y, Uzunhan Y, Toquet S, Leroux G, Gallay L, Marquet A, et al. Different phenotypes in dermatomyositis associated with antiMDA5 antibody. Neurology. (2020) 95:e70-e8. doi: 10.1212/WNL.0000000000 009727

7. Li Y, Li Y, Wu J, Miao M, Gao X, Cai W, et al. Predictors of poor outcome of anti-MDA5-associated rapidly progressive interstitial lung disease in a chinese cohort with dermatomyositis. J Immunol Res. (2020) 2020:18. doi: $10.1155 / 2020 / 2024869$

8. Mammen AL. Autoimmune myopathies: autoantibodies, phenotypes and pathogenesis. Nat Rev Neurol. (2011) 7:343-54. doi: 10.1038/nrneurol.2011.63

9. Sato S, Hirakata M, Kuwana M, Suwa A, Inada S, Mimori T, et al. Autoantibodies to a $140-\mathrm{kd}$ polypeptide, CADM-140, in Japanese patients with clinically amyopathic dermatomyositis. Arthritis Rheum. (2005) 52:1571-6. doi: 10.1002/art.21023

10. Baccala R, Hoebe K, Kono DH, Beutler B, Theofilopoulos AN. TLRdependent and TLR-independent pathways of type I interferon induction in systemic autoimmunity. Nat Med. (2007) 13:543-51. doi: 10.1038/ nm1590

11. Sato S, Hoshino K, Satoh T, Fujita T, Kawakami Y, Fujita T, et al. RNA helicase encoded by melanoma differentiation-associated gene 5 is a major autoantigen in patients with clinically amyopathic dermatomyositis: Association with rapidly progressive interstitial lung disease. Arthritis Rheum. (2009) 60:2193200. doi: 10.1002/art.24621

12. Nakashima R, Imura Y, Kobayashi S, Yukawa N, Yoshifuji H, Nojima T, et al. The RIG-I-like receptor IFIH1/MDA5 is a dermatomyositis-specific autoantigen identified by the anti-CADM-140 antibody. Rheumatology (Oxford). (2010) 49:433-40. doi: 10.1093/rheumatology/kep375

13. Chen K, Liu J, Cao X. Regulation of type I interferon signaling in immunity and inflammation: a comprehensive review. J Autoimmun. (2017) 83:111. doi: 10.1016/j.jaut.2017.03.008

14. Dias Junior AG, Sampaio NG, Rehwinkel J. A balancing act: MDA5 in antiviral immunity and autoinflammation. Trends Microbiol. (2019) 27:7585. doi: 10.1016/j.tim.2018.08.007

15. Jiang J, Zhao M, Chang C, Wu H, Lu Q. Type I Interferons in the pathogenesis and treatment of autoimmune diseases. Clin Rev Allergy Immunol. (2020) 59:248-72. doi: 10.1007/s12016-020-08798-2

\section{FUNDING}

This research was funded by grant from the National Natural Science Foundation of China (No. 81172870), 1.3.5 project for disciplines of excellence, West China Hospital, Sichuan University (No. ZYGD18015), 1.3.5 project for disciplines of excellence, West China Hospital, Sichuan University (No. ZYJC18003), and the Science and Technology Innovation and Entrepreneurship Seedling Project of Sichuan Province (No. 2019JDRC0101).

16. Brisse $\mathrm{M}$, Ly $\mathrm{H}$. Comparative structure and function analysis of the RIG-I-Like receptors: RIG-I and MDA5. Front Immunol. (2019) 10:1586. doi: 10.3389/fimmu.2019.01586

17. O'Neill LA, Bowie AG. The family of five: TIR-domain-containing adaptors in Toll-like receptor signalling. Nat Rev Immunol. (2007) 7:35364. doi: $10.1038 /$ nri2079

18. Loo YM, Gale M Jr. Immune signaling by RIG-I-like receptors. Immunity. (2011) 34:680-92. doi: 10.1016/j.immuni.2011.05.003

19. Kawai T, Akira S. Toll-like receptor and RIG-I-like receptor signaling. Ann N Y Acad Sci. (2008) 1143:1-20. doi: 10.1196/annals.1443.020

20. Blasius AL, Beutler B. Intracellular toll-like receptors. Immunity. (2010) 32:305-15. doi: 10.1016/j.immuni.2010.03.012

21. Muskardin TLW, Niewold TB. Type I interferon in rheumatic diseases. Nature Rev Rheumatol. (2018) 14:214-28. doi: 10.1038/nrrheum.2018.31

22. Ronnblom L, Alm GV, Eloranta ML. The type I interferon system in the development of lupus. Semin Immunol. (2011) 23:113-21. doi: 10.1016/j.smim.2011.01.009

23. Isaacs A, Lindenmann J. Virus interference. I The interferon. Proc R Soc Lond B Biol Sci. (1957) 147:258-67. doi: 10.1098/rspb.1957.0048

24. Ivashkiv LB, Donlin LT. Regulation of type I interferon responses. Nat Rev Immunol. (2014) 14:36-49. doi: 10.1038/nri3581

25. Ronnblom L. The importance of the type I interferon system in autoimmunity. Clin Exp Rheumatol. (2016) 34(4 Suppl 98):21-4.

26. Borden EC, Sen GC, Uze G, Silverman RH, Ransohoff RM, Foster GR, et al. Interferons at age 50: past, current and future impact on biomedicine. Nat Rev Drug Discov. (2007) 6:975-90. doi: 10.1038/nrd2422

27. Platanias LC. Mechanisms of type-I- and type-II-interferon-mediated signalling. Nat Rev Immunol. (2005) 5:375-86. doi: 10.1038/nri1604

28. Schneider WM, Chevillotte MD, Rice CM. Interferon-stimulated genes: a complex web of host defenses. Annu Rev Immunol. (2014) 32:51345. doi: 10.1146/annurev-immunol-032713-120231

29. Schoggins JW. Interferon-stimulated genes: what do they all do? Annu Rev Virol. (2019) 6:567-84. doi: 10.1146/annurev-virology-092818-015756

30. Barrat FJ, Crow MK, Ivashkiv LB. Interferon target-gene expression and epigenomic signatures in health and disease. Nat Immunol. (2019) 20:157483. doi: 10.1038/s41590-019-0466-2

31. Lazear HM, Schoggins JW, Diamond MS. Shared and distinct functions of type $\mathrm{i}$ and type iii interferons. Immunity. (2019) 50:907-23. doi: 10.1016/j.immuni.2019.03.025

32. Cao H, Pan M, Kang Y, Xia Q, Li X, Zhao X, et al. Clinical manifestations of dermatomyositis and clinically amyopathic dermatomyositis patients with positive expression of anti-melanoma differentiationassociated gene 5 antibody. Arthritis Care Res (Hoboken). (2012) 64:1602-10. doi: 10.1002/acr.21728

33. Fiorentino D, Chung L, Zwerner J, Rosen A, Casciola-Rosen L. The mucocutaneous and systemic phenotype of dermatomyositis patients with antibodies to MDA5 (CADM-140): a retrospective study. J Am Acad Dermatol. (2011) 65:25-34. doi: 10.1016/j.jaad.2010.09.016

34. LaFleur DW, Nardelli B, Tsareva T, Mather D, Feng P, Semenuk M, et al. Interferon-kappa, a novel type I interferon expressed in human keratinocytes. J Biol Chem. (2001) 276:39765-71. doi: 10.1074/jbc.M102502200

35. Cassius C, Amode R, Delord M, Battistella M, Poirot J, How-Kit A, et al. MDA5(+) dermatomyositis is associated with stronger skin type i interferon 
transcriptomic signature with upregulation of IFN-kappa transcript. J Invest Dermatol. (2020) 140:1276-9 e7. doi: 10.1016/j.jid.2019.10.020

36. Sarkar MK, Hile GA, Tsoi LC, Xing X, Liu J, Liang Y, et al. Photosensitivity and type I IFN responses in cutaneous lupus are driven by epidermal-derived interferon kappa. Ann Rheum Dis. (2018) 77:1653-64. doi: 10.1136/annrheumdis-2018-213197

37. Ono N, Kai K, Maruyama A, Sakai M, Sadanaga Y, Koarada S, et al. The relationship between type 1 IFN and vasculopathy in anti-MDA5 antibodypositive dermatomyositis patients. Rheumatology (Oxford). (2019) 58:78691. doi: 10.1093/rheumatology/key386

38. Cao H, Xia Q, Pan M, Zhao X, Li X, Shi R, et al. Gottron papules and gottron sign with ulceration: a distinctive cutaneous feature in a subset of patients with classic dermatomyositis and clinically amyopathic dermatomyositis. $J$ Rheumatol. (2016) 43:1735-42. doi: 10.3899/jrheum.160024

39. He C, Chen J, Luo X, Yan B. Evaluation of biomarkers related to endothelial dysfunction: proof of vasculopathy in anti-melanoma differentiationassociated gene 5 dermatomyositis. Clin Exp Rheumatol. (2021) 39:151-7.

40. Liang L, Zhang YM, Shen YW, Song AP, Li WL, Ye LF, et al. Aberrantly expressed Galectin-9 is involved in the immunopathogenesis of Anti-MDA5positive dermatomyositis-associated interstitial lung disease. Front Cell Dev Biol. (2021) 9:628128. doi: 10.3389/fcell.2021.628128

41. Allenbach Y, Leroux G, Suarez-Calvet X, Preusse C, Gallardo E, Hervier B, et al. Dermatomyositis with or without anti-melanoma differentiation-associated Gene 5 antibodies: common interferon signature but distinct NOS2 expression. Am J Pathol. (2016) 186:691-700. doi: 10.1016/j.ajpath.2015.11.010

42. Jiang Y, Liu Y, Zhao Y, Zheng Y, Yu M, Deng J, et al. Mitochondrial morphology and MAVS-IFN1 signaling pathway in muscles of anti-MDA5 dermatomyositis. Ann Clin Transl Neurol. (2021) 8:677-86. doi: 10.1002/acn3.51311

43. Horai Y, Koga T, Fujikawa K, Takatani A, Nishino A, Nakashima Y, et al. Serum interferon-alpha is a useful biomarker in patients with anti-melanoma differentiation-associated gene 5 (MDA5) antibody-positive dermatomyositis. Mod Rheumatol. (2015) 25:85-9. doi: 10.3109/14397595.2014.900843

44. Wang K, Zhao J, Wu W, Xu W, Sun S, Chen Z, et al. RNA-Containing immune complexes formed by anti-melanoma differentiation associated Gene 5 Autoantibody are potent inducers of IFN-alpha. Front Immunol. (2021) 12:743704. doi: 10.3389/fimmu.2021.743704

45. Matsushita T, Mizumaki K, Kano M, Yagi N, Tennichi M, Takeuchi A, et al. Antimelanoma differentiation-associated protein 5 antibody level is a novel tool for monitoring disease activity in rapidly progressive interstitial lung disease with dermatomyositis. Br J Dermatol. (2017) 176:395402. doi: $10.1111 /$ bjd. 14882

46. Chen F, Wang D, Shu X, Nakashima R, Wang G. Anti-MDA5 antibody is associated with A/SIP and decreased T cells in peripheral blood and predicts poor prognosis of ILD in Chinese patients with dermatomyositis. Rheumatol Int. (2012) 32:3909-15. doi: 10.1007/s00296-011-2323-y

47. Lian X, Zou J, Guo Q, Chen S, Lu L, Wang R, et al. Mortality risk prediction in amyopathic dermatomyositis associated with interstitial lung disease: the FLAIR model. Chest. (2020) 158:1535-45. doi: 10.1016/j.chest.2020.04.057

48. Bai J, Wu C, Zhong D, Xu D, Wang Q, Zeng X. Hierarchical cluster analysis of cytokine profiles reveals a cutaneous vasculitisassociated subgroup in dermatomyositis. Clin Rheumatol. (2021) 40:999-1008. doi: 10.1007/s10067-020-05339-2

49. Takada T, Aoki A, Asakawa K, Sakagami T, Moriyama H, Narita I, et al. Serum cytokine profiles of patients with interstitial lung disease associated with anti-CADM-140/MDA5 antibody positive amyopathic dermatomyositis. Respir Med. (2015) 109:1174-80. doi: 10.1016/j.rmed.2015.07.004

50. Hayashi M, Aoki A, Asakawa K, Sakagami T, Kikuchi T, Takada T. Cytokine profiles of amyopathic dermatomyositis with interstitial lung diseases treated with mycophenolate. Respirol Case Rep. (2017) 5:e00235. doi: 10.1002/rcr2.235

51. Nakano M, Fujii T, Hashimoto M, Yukawa N, Yoshifuji H, Ohmura K, et al. Type I interferon induces CX3CL1 (fractalkine) and CCL5 (RANTES) production in human pulmonary vascular endothelial cells. Clin Exp Immunol. (2012) 170:94-100. doi: 10.1111/j.1365-2249.2012.04638.x

52. Urban J, Suchankova M, Ganovska M, Leksa V, Sandor F, Tedlova $\mathrm{E}$, et al. The role of CX3CL1 and ADAM17 in pathogenesis of diffuse parenchymal lung diseases. Diagnostics (Basel). (2021) 11:1074. doi: 10.3390/diagnostics11061074

53. Ishida Y, Kimura A, Nosaka M, Kuninaka Y, Hemmi H, Sasaki I, et al. Essential involvement of the CX3CL1-CX3CR1 axis in bleomycin-induced pulmonary fibrosis via regulation of fibrocyte and M2 macrophage migration. Sci Rep. (2017) 7:16833. doi: 10.1038/s41598-017-17007-8

54. Greiffo FR, Viteri-Alvarez V, Frankenberger M, Dietel D, Ortega-Gomez A, Lee JS, et al. CX3CR1-fractalkine axis drives kinetic changes of monocytes in fibrotic interstitial lung diseases. Eur Respir J. (2020) 55:1900460. doi: 10.1183/13993003.00460-2019

55. Kurasawa K, Arai S, Namiki Y, Tanaka A, Takamura Y, Owada T, et al. Tofacitinib for refractory interstitial lung diseases in anti-melanoma differentiation-associated 5 gene antibody-positive dermatomyositis. Rheumatology (Oxford). (2018) 57:2114-9. doi: 10.1093/rheumatology/ key188

56. Chen Z, Wang X, Ye S. Tofacitinib in amyopathic dermatomyositisassociated interstitial lung disease. N Engl J Med. (2019) 381:2913. doi: 10.1056/NEJMc1900045

57. Sabbagh S, Almeida de. Jesus A, Hwang S, Kuehn HS, Kim H, Jung L, et al. Treatment of anti-MDA5 autoantibody-positive juvenile dermatomyositis using tofacitinib. Brain. (2019) 142:e59. doi: 10.1093/brain/awz293

58. Chou JW, Lin YL, Cheng KS, Wu PY, Reanne Ju T. Dermatomyositis induced by hepatitis B virus-related hepatocellular carcinoma: a case report and review of the literature. Intern Med. (2017) 56:1831-7. doi: 10.2169/internalmedicine.56.7595

59. Bowles NE, Dubowitz V, Sewry CA, Archard LC. Dermatomyositis, polymyositis, and Coxsackie-B-virus infection. Lancet. (1987) 1:10047. doi: 10.1016/S0140-6736(87)92271-9

60. Mamyrova G, Rider LG, Haagenson L, Wong S, Brown KE. Parvovirus B19 and onset of juvenile dermatomyositis. JAMA. (2005) 294:21701. doi: 10.1001/jama.294.17.2170

61. Muro Y, Sugiura K, Hoshino K, Akiyama M, Tamakoshi K. Epidemiologic study of clinically amyopathic dermatomyositis and anti-melanoma differentiation-associated gene 5 antibodies in central Japan. Arthritis Res Ther. (2011) 13:R214. doi: 10.1186/ar3547

62. Nishina N, Sato S, Masui K, Gono T, Kuwana M. Seasonal and residential clustering at disease onset of anti-MDA5-associated interstitial lung disease. RMD Open. (2020) 6:e001202. doi: 10.1136/rmdopen-2020001202

63. Chen $\mathrm{Z}$, Wang $\mathrm{Y}$, Kuwana $\mathrm{M}, \mathrm{Xu} \mathrm{X}, \mathrm{Hu} \mathrm{W}$, Feng $\mathrm{X}$, et al. HLADRB1 alleles as genetic risk factors for the development of Anti-MDA5 antibodies in patients with dermatomyositis. J Rheumatol. (2017) 44:138993. doi: $10.3899 /$ jrheum. 170165

64. Gono T, Kawaguchi Y, Kuwana M, Sugiura T, Furuya T, Takagi K, et al. Brief report: association of HLA-DRB1*0101/*0405 with susceptibility to anti-melanoma differentiation-associated gene 5 antibody-positive dermatomyositis in the Japanese population. Arthritis Rheum. (2012) 64:3736-40. doi: 10.1002/art.34657

65. Rothwell S, Chinoy H, Lamb JA, Miller FW, Rider LG, Wedderburn LR, et al. Focused HLA analysis in Caucasians with myositis identifies significant associations with autoantibody subgroups. Ann Rheum Dis. (2019) 78:9961002. doi: 10.1136/annrheumdis-2019-215046

66. Kochi Y, Kamatani Y, Kondo Y, Suzuki A, Kawakami E, Hiwa R, et al. Splicing variant of WDFY4 augments MDA5 signalling and the risk of clinically amyopathic dermatomyositis. Ann Rheum Dis. (2018) 77:60211. doi: 10.1136/annrheumdis-2017-212149

67. Wang K, Zhao J, Chen Z, Li T, Tan X, Zheng Y, et al. CD4+CXCR4+ T cells as a novel prognostic biomarker in patients with idiopathic inflammatory myopathy-associated interstitial lung disease. Rheumatology (Oxford). (2019) 58:511-21. doi: 10.1093/rheumatology/key341

68. Vincent FB, Saulep-Easton D, Figgett WA, Fairfax KA, Mackay F. The BAFF/APRIL system: emerging functions beyond $B$ cell biology and autoimmunity. Cytokine Growth Factor Rev. (2013) 24:203-15. doi: 10.1016/j.cytogfr.2013.04.003

69. Nardelli B, Belvedere O, Roschke V, Moore PA, Olsen HS, Migone TS, et al. Synthesis and release of B-lymphocyte stimulator from myeloid cells. Blood. (2001) 97:198-204. doi: 10.1182/blood.V97.1.198 
70. Matsushita T, Kobayashi T, Kano M, Hamaguchi Y, Takehara K. Elevated serum B-cell activating factor levels in patients with dermatomyositis: association with interstitial lung disease. J Dermatol. (2019) 46:11906. doi: 10.1111/1346-8138.15117

71. Zhang SH, Zhao Y, Xie QB, Jiang Y, Wu YK, Yan B. Aberrant activation of the type I interferon system may contribute to the pathogenesis of anti-melanoma differentiation-associated gene 5 dermatomyositis. Br J Dermatol. (2019) 180:1090-8. doi: 10.1111/bjd. 16917

72. Lee JS, Lee EY, Ha YJ, Kang EH, Lee YJ, Song YW. Serum KL-6 levels reflect the severity of interstitial lung disease associated with connective tissue disease. Arthritis Res Ther. (2019) 21:58. doi: 10.1186/s13075-0191835-9

73. Kalled SL. The role of BAFF in immune function and implications for autoimmunity. Immunol Rev. (2005) 204:4354. doi: 10.1111/j.0105-2896.2005.00219.x

74. Chen M, Zhao Q, Diao L, Xue K, Ruan Y, Xue F, et al. Distribution of anti-melanoma differentiation associated gene 5 (MDA5) IgG subclasses in MDA5+ dermatomyositis. Rheumatology (Oxford). (2021) 61:430-9. doi: 10.1093/rheumatology/keab268

75. Kretschmer S, Lee-Kirsch MA. Type I interferon-mediated autoinflammation and autoimmunity. Curr Opin Immunol. (2017) 49:96-102. doi: 10.1016/j.coi.2017.09.003

76. Gono T, Miyake K, Kawaguchi Y, Kaneko H, Shinozaki M, Yamanaka H. Hyperferritinaemia and macrophage activation in a patient with interstitial lung disease with clinically amyopathic DM. Rheumatology (Oxford). (2012) 51:1336-8. doi: 10.1093/rheumatology/ kes012

77. Horiike Y, Suzuki Y, Fujisawa T, Yasui H, Karayama M, Hozumi $\mathrm{H}$, et al. Successful classification of macrophage-mannose receptor CD206 in severity of anti-MDA5 antibody positive dermatomyositis associated ILD. Rheumatology (Oxford). (2019) 58:2143-52. doi: 10.1093/rheumatology/kez185
78. Gono T, Okazaki Y, Kuwana M. Antiviral proinflammatory phenotype of monocytes in anti-MDA5 antibody-associated interstitial lung disease. Rheumatology (Oxford). (2021). doi: 10.1093/rheumatology/keab371

79. Gschwandtner M, Derler R, Midwood KS. More than just attractive: how CCL2 influences myeloid cell behavior beyond chemotaxis. Front Immunol. (2019) 10:2759. doi: 10.3389/fimmu.2019.02759

80. Zuo Y, Ye L, Liu M, Li S, Liu W, Chen F, et al. Clinical significance of radiological patterns of HRCT and their association with macrophage activation in dermatomyositis. Rheumatology (Oxford). (2020) 59:282937. doi: 10.1093/rheumatology/keaa034

81. Higgs BW, Zhu W, Morehouse C, White WI, Brohawn P, Guo X, et al. A phase $1 \mathrm{~b}$ clinical trial evaluating sifalimumab, an anti-IFN-alpha monoclonal antibody, shows target neutralisation of a type I IFN signature in blood of dermatomyositis and polymyositis patients. Ann Rheum Dis. (2014) 73:25662. doi: 10.1136/annrheumdis-2012-202794

Conflict of Interest: The authors declare that the research was conducted in the absence of any commercial or financial relationships that could be construed as a potential conflict of interest.

Publisher's Note: All claims expressed in this article are solely those of the authors and do not necessarily represent those of their affiliated organizations, or those of the publisher, the editors and the reviewers. Any product that may be evaluated in this article, or claim that may be made by its manufacturer, is not guaranteed or endorsed by the publisher.

Copyright (C) $2022 \mathrm{Hu}$, Yang, Liu and Yan. This is an open-access article distributed under the terms of the Creative Commons Attribution License (CC BY). The use, distribution or reproduction in other forums is permitted, provided the original author(s) and the copyright owner(s) are credited and that the original publication in this journal is cited, in accordance with accepted academic practice. No use, distribution or reproduction is permitted which does not comply with these terms. 